\title{
Dysphagia Lusoria: An Elusive Diagnosis
}

\author{
Georgy Kaspar*, Nicholas A Battista, Delano Small and Christian Machado \\ Department of Internal Medicine, Providence-Providence Park Hospital, USA
}

Submission: March 08, 2017; Published: May 03, 2017

*Corresponding author: Georgy Kaspar, Department of Internal Medicine, Division of Cardiology, Providence-Providence Park Hospital, Southfield, Michigan, USA, Tel: 561-309-9075; Email: geokaspar@hotmail.com

\section{Introduction}

Dysphagia lusoria is a sporadic condition that causes difficulty swallowing. The symptoms are attributed to an aberrant right subclavian artery that has a retroesophageal course leading to vascular compression of the esophagus.

Dysphagia lusoria is an uncommon anomaly and even rarer cause of symptoms. However, when symptomatic and occurring in conjunction with similar presenting conditions, it can create a diagnostic and treatment challenge [1].

\section{Case Report}

A 62-year-old female with a medical history significant for coronary artery disease and gastritis presented to our hospital on multiple occasions complaining of chronic nausea, dyspnea, chest pain and dysphagia. Physical examination was often unrevealing with the exception of hypertensive blood pressure. Laboratory investigation often included complete blood cell count, complete metabolic panel, serial troponins, D-Dimers, all usually within normal limits.

Multiple subspecialists, most commonly being gastroenterologists and cardiologists, were consulted to evaluate her. Despite an extensive medical workup, including esophagogastroduodenoscopy, computerized tomography (CT) scans of the thorax, abdomen and pelvis, magnetic resonance angiogram (MRA) of the abdomen and multiple echocardiograms, the cause of her symptoms remained elusive.

Prior to her diagnosis, she had a total of twelve emergency department visits and five hospitalizations before a coronary CT was utilized. Her coronary CT revealed an anomalous origin of the left coronary artery from the right coronary cusp with a retroaortic course in addition to the left aortic arch exhibiting an aberrant right subclavian artery (Figures 1 \& 2).
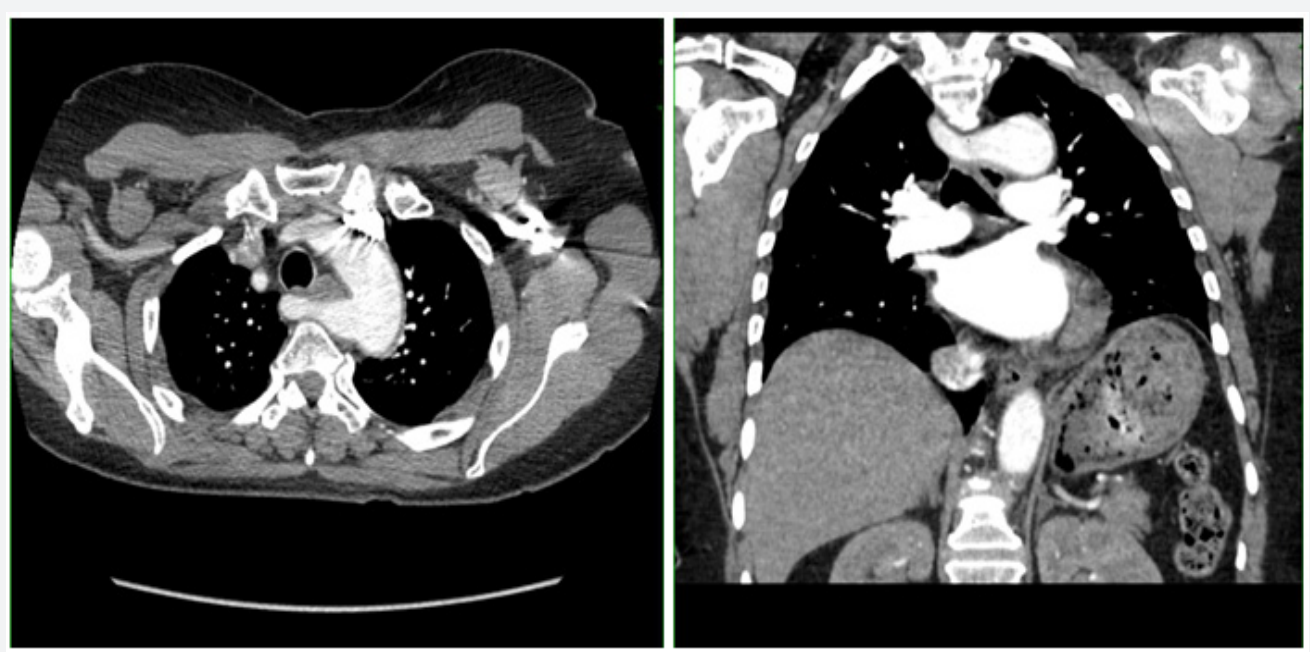

Figures 1 \& 2: CT revealed an anomalous origin of the left coronary artery from the right coronary cusp with a retroaortic course in addition to the left aortic arch exhibiting an aberrant right subclavian artery. 
Hence, a diagnosis of Dysphagia Lusoria was made and the patient was referred to cardiothoracic surgery. Typically, surgical treatment is the only curative option, however, symptoms can be controlled by specific dietary modifications, the use of proton pump inhibitors and antianginal medication. Our patient has opted for conservative medical management while exploring the possibility of surgical correction but symptoms still persist.

\section{Discussion}

Dysphagia lusoria is a term used to designate dysphagia as a result of vascular compression of the esophagus. It was first utilized by Bayford [2] in 1761 in describing a case of longstanding dysphagia leading to emaciation and eventual death of a 62-year old female patient. On autopsy the patient was found to have an aberrant right subclavian artery running anterior to and causing compression of her esophagus. This is a common variant of embryonic aortic arch involution within the general population. It is estimated at $0.4 \%$ to $0.7 \%$ in e published literature [3]. 30\%-40\% of patients with vascular anomalies have dysphagia, with the majority presenting with solid bolus dysphagia.

Traditionally, catheter angiogram has been accepted as a gold standard tool for diagnosis. Nevertheless, today with the availability of 3D spiral CT angiography and 3D MRA, we can non-invasively demonstrate such vascular anomalies. Also, some references mention dynamic barium swallow studies as a diagnostic screening tool for dysphagia lusoria.

The management is reliant on the severity of symptoms and impact on the ability of the patients to maintain their weight and nutrition. It is imperative to first treat these patients with prokinetic, anti-reflux drugs or dietary modification.
Only if the symptoms are intractable should these patients be subjected to surgical correction of the anomaly. In addition, the decision to operate also depends on the presence of an aneurysm near the root of the artery, and the age of the patient. The most common approach to repair is a left postero-lateral thoracotomy followed by division and ligation of the aberrant artery with dissection or possible re-implant [4].

After thorough investigation of literature, we did not find any association between anomalous origin of the left coronary artery and aberrant right subclavian artery. Hence, this is the first case report to raise the question of a common embryologic etiology that may lead to both anomalies.

\section{Conclusion}

a) The lusorian artery can create a diagnostic and treatment challenge.

b) Contrast enhanced CT or MRI can easily confirm the diagnosis and demonstrate the exact relationship of the anomalous vessel with surrounding structures.

c) Operative repair by open surgery or in combination with endovascular techniques is recommended to treat symptoms and reduce the risk of aneurysm rupture.

\section{References}

1. Kent PD, Poterucha TH (2002) Aberrant Right Subclavian Artery and Dysphagia Lusoria. New England Journal of Medicine 346: 1637.

2. Asherson N (1979) David Bayford. His syndrome and sign of dysphagia lusoria. Ann R Coll Surg Engl 61(1): 63-67.

3. Levitt B, Richter JE (2007) Dysphagia lusoria: a comprehensive review. Dis Esophagus 20(6): 455-460.

4. Morris CD, Kanter KR, Miller JI (2001) Late-onset dysphagia lusoria. Ann Thorac Surg 71(2): 710-712.

\section{Your next submission with Juniper Publishers will reach you the below assets}

- Quality Editorial service

- Swift Peer Review

- Reprints availability

- E-prints Service

- Manuscript Podcast for convenient understanding

- Global attainment for your research

- Manuscript accessibility in different formats

( Pdf, E-pub, Full Text, Audio)

- Unceasing customer service

Track the below URL for one-step submission https://juniperpublishers.com/online-submission.php 